\title{
Sistem Stabilisasi Nampan Menggunakan IMU Sensor dan Arduino Nano
}

\author{
Abu Hatim Kurniawan dan Muhammad Rivai \\ Departemen Teknik Elektro, Fakultas Teknologi Elektro, Institut Teknologi Sepuluh Nopember \\ e-mail: muhammad_rivai@ee.its.ac.id
}

\begin{abstract}
Abstrak-Penderita penyakit parkinson kerap kali mengalami kesulitan dalam membawa sesuatu barang. Hal ini dikarenakan berkurangnya kemampuan syaraf motorik sehingga mengakibatkan beberapa bagian tubuh bergetar terutama tangan. Pada saat ini belum terdapat suatu media yang digunakan untuk membawa makanan atau barang yang stabil terhadap goncangan. Pada penelitian ini diusulkan membuat suatu nampan yang seimbang dengan menggunakan Inertial Measurement Unit (IMU) Sensor MPU6050. Sensor tersebut mampu mendeteki perubahan sudut atau posisi pada 3 dimensi. Sistem ini menggunakan mikrokontroler Arduino Nano sebagai pemroses sinyal yang diberikan oleh sensor. Mikrokontroler ini mempunyai pin input/output baik digital maupun analog dan Analog To Digital Convertion (ADC) pada mikrokontroler tersebut mampu untuk mengolah output sensor. Bentuk fisik Arduino Nano mempunyai ukuran yang kecil sehingga portable dan tidak terlalu berat dalam stabilisator tersebut. Nilai galat yang merupakan selisih antara setting point dan keluaran sensor tersebut kemudian akan digunakan sebagai sinyal masukan kontroler Proportional Integrator Derivative (PID). Motor servo digunakan sebagai aktuator yang akan bergerak sesuai dengan besarnya galat, sehingga akan menghasilkan kestabilan gerakan nampan. Hasil pengujian sistem success rate stabilisator ketika sistem tanpa beban adalah sebesar $100 \%$ untuk keadaan diam dan $60 \%$ ketika keadaan berjalan. Sedangkan pada keadaan dengan beban didapatkan success rate sebesar $\mathbf{7 0 \%}$ pada keadaan diam dan $\mathbf{6 0 \%}$ saat keadaan berjalan. Hasil penelitian ini diharapkan mengurangi resiko jatuh atau tumpahnya barang atau makanan terutama pada saat dibawa oleh penderita parkinson.
\end{abstract}

Kata Kunci-IMU Sensor, Kontroler Proportional, Stabilisator.

\section{PENDAHULUAN}

$\mathrm{P}$ ERKEMBANGAN teknologi belakangan ini berkembang sangat cepat, banyak sekali terobosan-terobosan yang mendukung kehidupan manusia. Namum perkembangan tersebut belum sampai menjangkau perkembangan teknologi untuk penderita penyakit parkinson. Para penderita penyakit parkinson kerap kali mengalami kesulitan dalam menjaliani kehidupan sehari-hari, terutama pada saat mereka hendak membawa makanan yang akan mereka makan. Pada saat ini mereka hanya membawa makanan pada nampan yang membuat mereka mengalami kesulitan karena makanan kerap kali tumpah yang diakibatkan oleh bergetarnya tangan mereka. Hal ini dikarenakan pada penderita sindrom parkinson mengalami melemahnya kemampuan syaraf motorik yang mengakibatkan mereka kesulitan dalam mengontrol anggota tubuh [1][2]. Penggunaan suatu sistem stabilisasi pada nampan akan memudahkan penderita parkinson dalam membawa makanan ataupun barang tanpa harus menjatuhkannya. Stabilisator ini menggunakan Inertial Measurement Unit (IMU) Sensor yang mampu mendeteksi perubahan posisi suatu benda. Pennggunaan metode kontrol proportional integrator derivative (PID) menjadikan stabilisator makin cepat dalam mencapai keadaan stabil. Dalam menentukan nilai PID bergantung pada jenis plant yang digunakan, dimana plant merupakan perangkat keras yang dikontrol. Misal pada motor servo, perbedaan jenis motor servo juga mempengaruhi nilai PID untuk mendapatkan hasil akurasi yang terbaik dan meminimalkan galat. Salah satu kekuatan PID adalah untuk jenis plant sederhana ada korelasi langsung antara respon plant, penggunaan dan penyesuaian dari tiga istilah kontroler [3]. Salah satu cara yang sering digunakan untuk mendapatkan nilai PID terbaik adalah menggunakan metode zieger Nichols serta trial and error. Dengan mengubah-ubah nilai PID pada coding dan dicoba pada hardware hingga mendapatkan hasil yang terbaik. Dari berbagai riset mengenai PID ini yang mempengaruhi nilai PID adalah jenis plant. Selain jenis plant yang digunakan, mikrokontroler juga dapat mempengaruhi nilai PID dengan mengesampingkan berbagai macam kebutuhan sistem terhadap mikrokontroler. Tiap mikrokontroler memiliki kecepatan proses, cara memproses coding dan juga pin-pin yang berbeda. Pada penelitian ini akan dirancang dan diimplementasikan suatu sistem stabilisasi nampan dengan menggukanak arduino nano dan IMU Sensor. Untuk mempercepat dalam mencapai suatu kestabilan digunakan kontrol Proportional-Integral-Derivative (PID) yang dikontrol secara close loop. Perubahan sudut dari nampan akan terbaca oleh IMU Sensor. Dimana, nilai keluaran sensor akan dibandingkan dengan nilai setpoint dari sistem.

\section{DASAR TEORI}

A. Kontroler PID

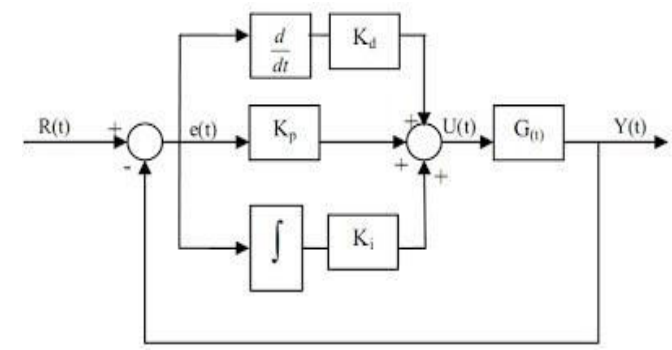

Gambar 1. Kontrol PID. 
Kontroler PID (Proporsional Integral Derivative) merupakan suatu metode kontrol yang digunakan untuk mencapai sebuah kesetimbangan [4],[5],[6], dan [7]. Penerapan kontroler PID juga digunakan untuk mengatur suhu suatu sistem [8], juga dapat digunakan untuk mengatur kecepatan motor pada suatu quadcopter [9]. Kontrol proporsional berfungsi untuk memperkuat sinyal kesalahan penggerak (sinyal error), sehingga akan mempercepat keluaran sistem mencapai titik referensi. Hubungan antara masukan kontroler $u(t)$ dengan sinyal galat $e(t)$, dapat dirumuskan pada persamaan (1).

$$
K_{p} \cdot e(t)
$$

Kontrol integral pada prinsipnya bertujuan untuk menghilangkan kesalahan keadaan tunak (offset) yang biasanya dihasilkan oleh kontrol proporsional. Hubungan antara keluaran kontrol integral $\mathrm{u}(\mathrm{t})$ dengan sinyal galat $\mathrm{e}(\mathrm{t})$ dapat dirumuskan pada persamaan (2). Blok diagram kontroler proporsional dapat kita lihat pada gambar 2 dibawah ini:

$$
K_{i} \cdot \int_{0}^{t} e(t) \phi t
$$

Kontrol derivative dapat disebut pengendali laju, karena keluaran kontroler sebanding dengan laju perubahan sinyal galat. Hubungan antara keluaran kontrol derivatif $u(t)$ dengan sinyal error e(t) dapat dirumuskan pada persamaan (3). Kontrol derivatif tidak akan pernah digunakan sendirian, karena kontroler ini hanya akan aktif pada periode peralihan. Pada periode peralihan, kontrol derivatif menyebabkan adanya redaman pada sistem sehingga lebih memperkecil lonjakan. Seperti pada kontrol proporsional, kontrol derivatif juga tidak dapat menghilangkan offset.:

$$
K_{d} \cdot \frac{\delta e(t)}{\delta t}
$$

\section{B. IMU Sensor}

Inertial Measurement Unit (IMU) Merupakan suatu sensor yang digunakan untuk mengukur kecepatan, orientasi dan gaya gravitasi dengan menggunakan sensor accelerometer dan gyroscope. IMU seringkali digunakan dalam suatu sistem pesawat terbang. Komponen penyusun IMU yang pertama adalah sensor accelerometer, sensor ini digunakan untuk mengukur percepatan dari suatu benda dengan cara melakukan integral percepatan benda tersebut terhadap waktu. Komponen selanjutnya yang menyusun IMU Sensor adalah sensor gyro, cara kerja sensor ini mendeteksi gerakan sesuai gravitasi, atau dengan kata lain mendeteksi gerakan pengguna. Gyroscope memiliki keluaran berupa kecepatan sudut dari arah 3 sumbu yaitu: sumbu x / sudut phi (kanan dan kiri) dari sumbu y/sudut theta (atas dan bawah), dan sumbu $\mathrm{z}$ /sudut psi (depan dan belakang) [10],[11], dan [12] seperti yang ditunjukkan pada gambar 2. Sensor MPU 6050 merupakan salah satu sensor yang menggunakan prinsip dasar IMU Sensor. Pengaturan register pada MPU-6050 dilakukan oleh mikrokontroler dengan komunikasi I2C [13][14].

\section{Arduino Nano}

Arduino Nano merupakan suatu papan pengembang mikrokontroler yang menggunakan chip ATmega328P, Arduino Nano bekerja pada masukan tegangan 5-7 Volt.
Terdapat memori flash sebesar $32 \mathrm{~KB}$ dan mampu bekerja pada clock 16 Mhz seperti yang ditunjukkan pada gambar 6 . Arduino nano dapat diprogram dengan menggunakan Arduino Integrated Development Environment (IDE) dan dihubungkan dengan kabel USB type B. Pada arduino nano terdapat 14 buah pin masukan dan keluaran, dimana 6 buah pin diantranya dapat digunakan untuk keluaran pulse width modulation (PWM). Terdapat 8 buah pin analog yakni A1, A2, A3, A4, A5, A6, A7 dan A8, keseluruhan pin analog ini terhubung dengan Analog to Digital Converter (ADC) pada internal mikrokontoler. Pada arduino nano juga tersedia dua buah pin SDA dan SCL (masing-masing pada A4 dan A5) yang dapat digunakan untuk komunikasi I2C seperti yang ditunjukkan pada gambar berikut [15].

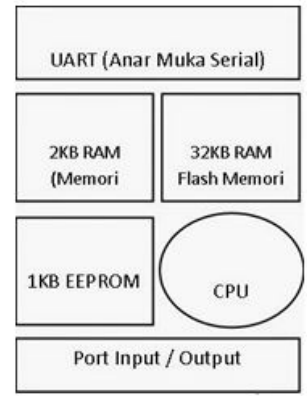

Gambar 2. Blok diagram arduino nano.

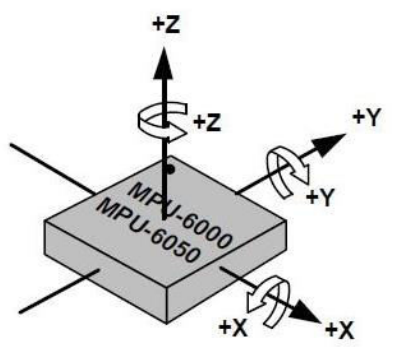

Gambar 3. Komponen penyusun IMU.

\section{Motor Servo}

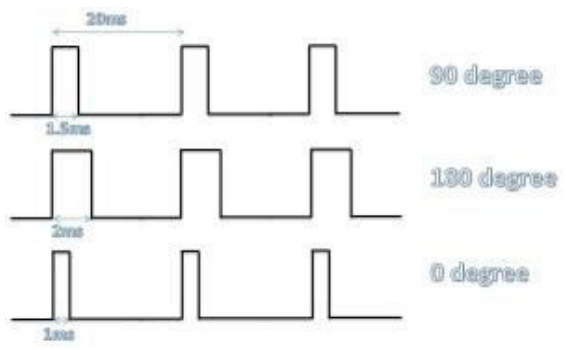

Gambar 4. Bentuk pulsa kendali motor servo.

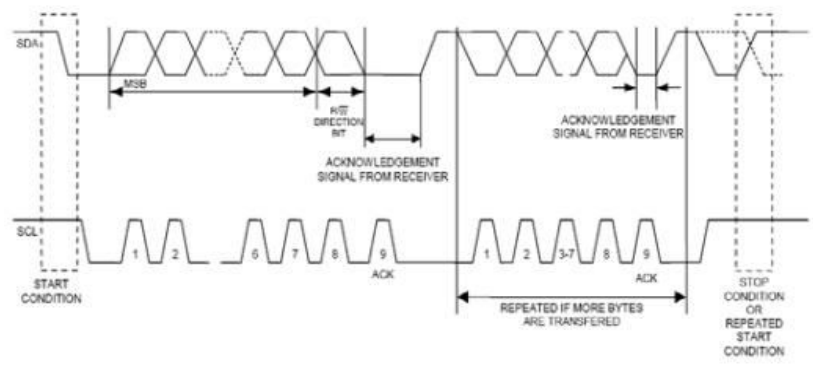

Gambar 5. Prinsip Komunikasi Serial Bus I2C. 
Motor servo merupakan motor yang bekerja berdasarkan cara kerja closed loop sehingga dapat diatur seberapa besar sudut putaran motor servo. Pengaturan sudut motor servo dapat diatur dengan menggunakan masukan Pulse Witdh Modulation (PWM). Besarnya torsi yang digunakan pada tipe motor servo SG90 adalah $9.40 \mathrm{Kg}-\mathrm{cm}$, dengan torsi sebesar itu kiranya sudah cukup digunakan untuk memutar poros motor servo. Untuk mengendalikan motor servo berbeda dengan motor DC biasa dapat mengendalikan motor servo perlu adanya PWM (Pulse Width Modulation) [16].

\section{E. Komunikasi I2C}

I2C singkatan dari Inter Integrated Circuit, adalah sebuah protokol untuk komunikasi serial antar IC, dan sering disebut juga Two Wire Interface (TWI). Bus yang digunakan untuk komunikasi antara mikrokontroler dan divais periferal seperti memori, sensor temperatur dan I/O expander. Komunikasi dilakukan melalui dua jalur: SDA (serial data) dan SCL (serial clock). Setiap divais I2C memiliki 7-bit alamat yang unik [17],[18], dan [19] seperti pada Gambar 5.

\section{PERANCANGAN ALAT}

\section{A. Perancangan Sistem}

Perencanaan sistem ini bertujuan agar sistem stabilisator dapat mengkoreksi sinyal galat yang merupakan perubahan sudut yang dideteksi oleh IMU Sensor. Sistem bekerja berdasarkan perubahan sudut yang terjadi secara signifikan. Pada alat ini terdapat beberapa bagian seperti sensor, mikrokontroler serta actuator. Pada bagian sensor terdapat IMU Sensor dengan tipe MPU6050 yang akan mendeteksi perubahan sudut akibat adanya guncangan yang terjadi pada sistem. Perubahan sudut yang dapat mampu dideteksi oleh sensor ialah pada sudut yaw, pitch dan roll. Dari data perubahan tersebut data yang diambil hanya pada sudut yaw dan pitch saja dikarenakan stabilisator hanya menggunakan dua axis saja. Sebelum ditambah sinyal kontrol, data dari MPU6050 akan difilter menggunakan exponential filter. Exponential filter merupakan filter frekuensi rendah yang menepis frekuensi tinggi pada suatu sinyal. Proses pemberian filter dilakukan oleh mikrokontroler, pada penelitian ini menggunakan mikrokontroler arduino nano. Kemudian $R A W$ Data (data mentah) hasil pembacaan MPU6050 akan diproses oleh mikrokontroler untuk dijadikan sudut, pada mikrokontroler juga bertugas untuk memberikan variabel kontrol pada perubahan sudut tersebut agar sinyal kontrol yang diteruskan aktuator. Pada aktuator terdiri dari dua buah motor servo yang masing-masing mewakili sudut yaw dan sudut pitch, masukan untuk aktuator merupakan sudut koreksi. Aktuator akan memberikan sinyal koreksi secara langsung yang diakibatkan oleh perubahan sudut, sinyal koreksi akan ditambah dengan sinyal kontrol agar mampu mencapai keadaan setimbang lebih cepat.

\section{B. Perancangan Software}

Perancangan perangkat lunak pada sistem ini yaitu mengontrol permukaan nampan agar tetap stabil ketika mendapat guncangan Perangkat lunak yang digunakan dalam membuat software yaitu Arduino IDE.

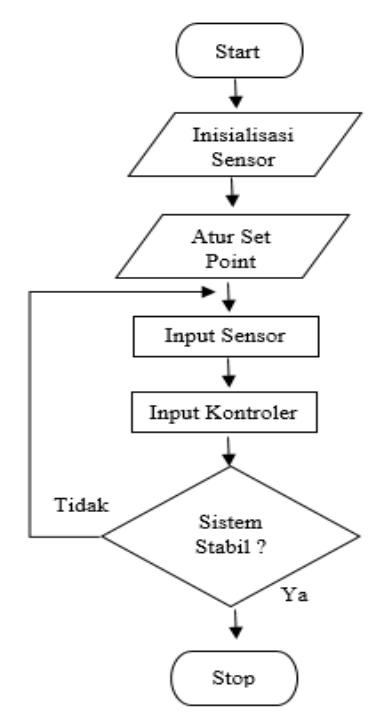

Gambar 6. Flowchart program.

Pada gambar diatas dapat kita lihat diagram alur flowchart pada penelitian ini, dimulai dengan inisialisasi sensor yang digunakan pada penelitian ini yakni IMU Sensor dengan tipe MPU6050. Setelah itu diberikan suatu nilai setpoint sebagai acuan dari pembacaan nilai sensor, dengan menggunakan suatu nilai variable kontrol maka akan tetap menjaga nampan pada sistem ini tetap stabil.

\section{Perancangan Mekanik}

Pada sub bab ini akan membahas tentang perancangan mekanik untuk penelitian ini. Perancangan mekanik berupa perancangan perangkat keras yang berguna untuk mendukung seluruh perancangan dan pembuatan alat. Perancangan mekanik yang akan dibahas yakni mengenai perancangan base dan perancangan bracket servo. Base yang digunakan pada stabilisator dicetak dengan menggunakan metode 3D Printing, dengan menggunakan bahan plastik ABS (Acrylonitrile Butadiene Styrene) yang mempunyai karakteristik kuat dan tidak gampang pecah akan membuat base yang digunakan menjadi kokoh dalam menopang keseluruhan beban. Pada gambar

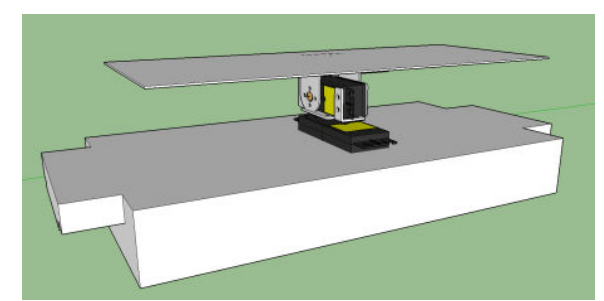

Gambar 7. Desain Base stabilisator tampak samping.

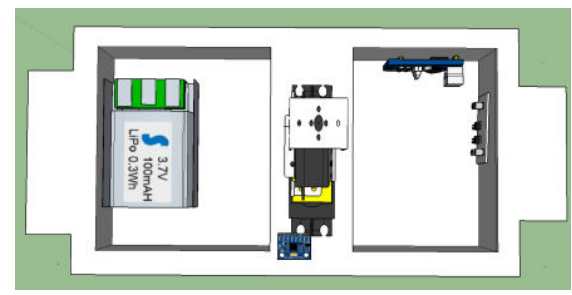

Gambar 8. Desain Base stabilisator tampak atas. 


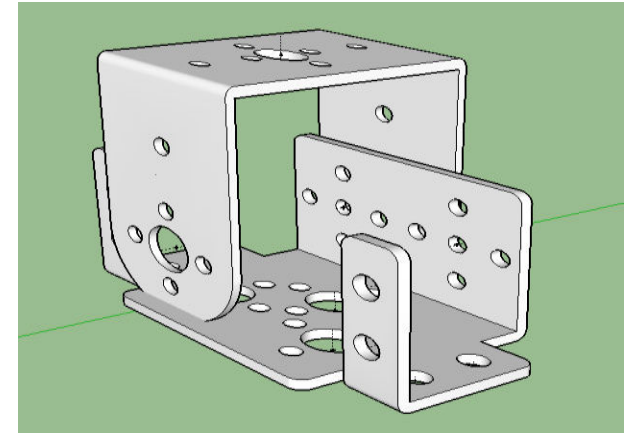

Gambar 9. Bracket tanpa servo.

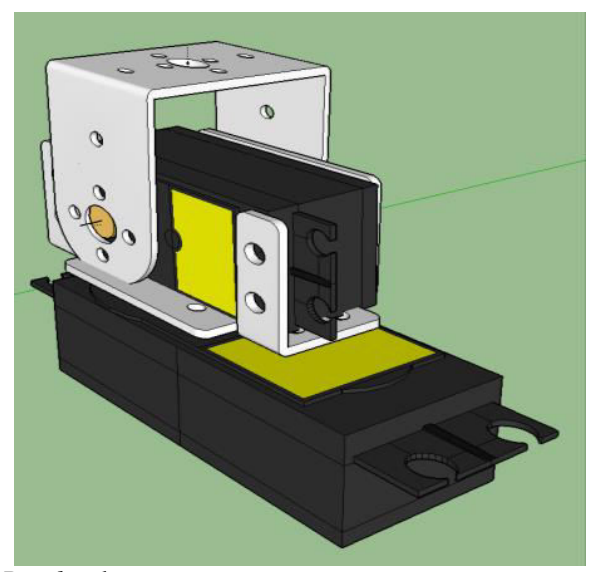

Gambar 10. Bracket dengan servo.

\section{PENGUJIAN DAN PEMBAHASAN}

\section{A. Pengujian Motor Servo}

Pengukuran dilakukan untuk kedua servo yang berfungsi sebagai actuator, yakni servo A (actuator yaw) dan servo B (actuator pitch). Cara pengujian ialah dengan memberikan besaran derajat dari arduino dan membandingkan hasil keluaran tersebut dengan menggunakan suatu penggaris busur untuk mengetahui nilai besarnya sudut.

Tabel 1.

Hasil Pengukuran Servo A dan Servo B

\begin{tabular}{|c|c|c|}
\hline Input A & Output A & Niai Galat \\
\hline 0 & 0 & 0 \\
\hline 10 & 11 & 0.1 \\
\hline 20 & 24 & 0.2 \\
\hline 30 & 31 & 0.0333333 \\
\hline 40 & 45 & 0.125 \\
\hline 50 & 52 & 0.04 \\
\hline 60 & 61 & 0.0166667 \\
\hline 70 & 72 & 0.0285714 \\
\hline 80 & 84 & 0.05 \\
\hline 90 & 91 & 0.0111111 \\
\hline 100 & 105 & 0.05 \\
\hline 110 & 118 & 0.0727273 \\
\hline 120 & 125 & 0.0416667 \\
\hline 130 & 138 & 0.0615385 \\
\hline 140 & 141 & 0.0071429 \\
\hline 150 & 157 & 0.0466667 \\
\hline 160 & 165 & 0.03125 \\
\hline 170 & 172 & 0.0117647 \\
\hline 180 & 185 & 0.0277778 \\
\hline galat rata-rata & 0.0530676 \\
\hline
\end{tabular}

\begin{tabular}{|c|c|c|}
\hline Input B & Output B & Nilai Galat \\
\hline 0 & 0 & 0 \\
\hline 10 & 12 & 0.2 \\
\hline 20 & 21 & 0.05 \\
\hline 30 & 32 & 0.0666667 \\
\hline 40 & 41 & 0.025 \\
\hline 50 & 51 & 0.02 \\
\hline 60 & 62 & 0.0333333 \\
\hline 70 & 73 & 0.0428571 \\
\hline 80 & 83 & 0.0375 \\
\hline 90 & 92 & 0.0222222 \\
\hline 100 & 102 & 0.02 \\
\hline 110 & 115 & 0.0454545 \\
\hline 120 & 121 & 0.0083333 \\
\hline 130 & 137 & 0.0538462 \\
\hline 140 & 143 & 0.0214286 \\
\hline 150 & 152 & 0.0133333 \\
\hline 160 & 162 & 0.0125 \\
\hline 170 & 173 & 0.0176471 \\
\hline 180 & 181 & 0.0055556 \\
\hline \multicolumn{2}{|c|}{ Galat rata-rata } & 0.0386488 \\
\hline
\end{tabular}

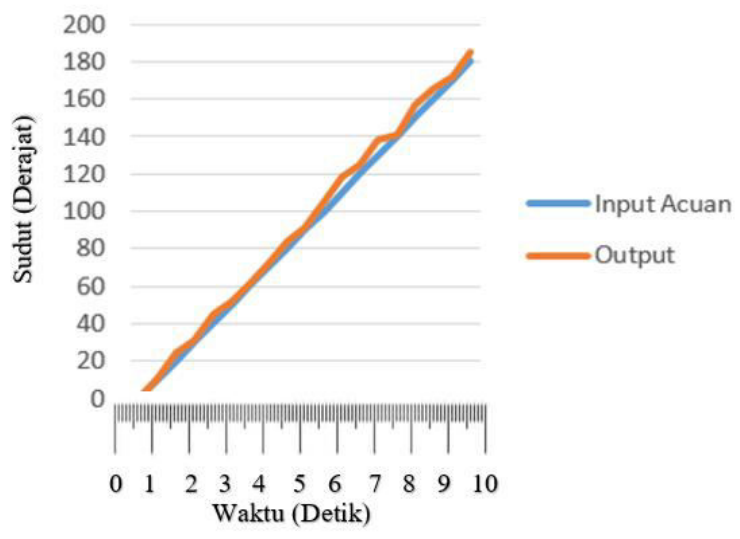

Gambar 11. Liniearisasi Servo A.

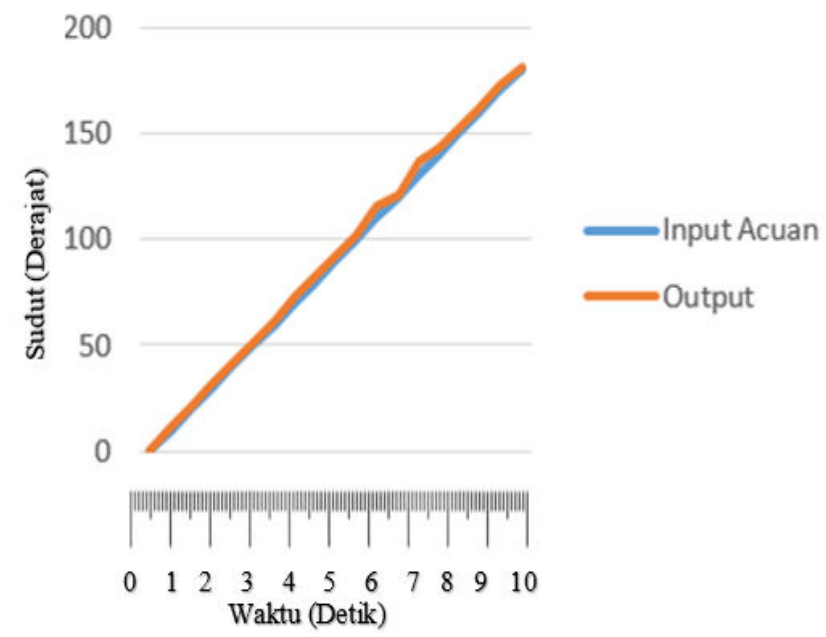

Gambar 12. Liniearisasi Servo B.

\section{B. Pengujian Motor servo}

Pengujian pada IMU Sensor bertujuan untuk mengetahui kesesuaian sudut antara sensor dengan acuan, kedua hal tersebut haruslah sama karena IMU Sensor digunakan untuk mengetahui perubahan sudut pada stabilisator.

Tabel 2.

Hasil Pengujian IMU Sensor.

\begin{tabular}{ccc}
\hline \hline Sudut Acuan & Output Sensor Yaw & Output Sensor Roll \\
\hline 10 & 12 & 11 \\
20 & 19 & 21 \\
30 & 29 & 30 \\
40 & 39 & 42 \\
50 & 49 & 51 \\
60 & 59 & 61 \\
70 & 75 & 72 \\
80 & 89 & 81 \\
90 & 99 & 91 \\
100 & 108 & 102 \\
110 & 118 & 109 \\
120 & 128 & 118 \\
130 & 138 & 131 \\
140 & 148 & 139 \\
150 & 158 & 151 \\
160 & 169 & 163 \\
170 & 179 & 172 \\
180 & -18 & 178 \\
\hline \hline
\end{tabular}




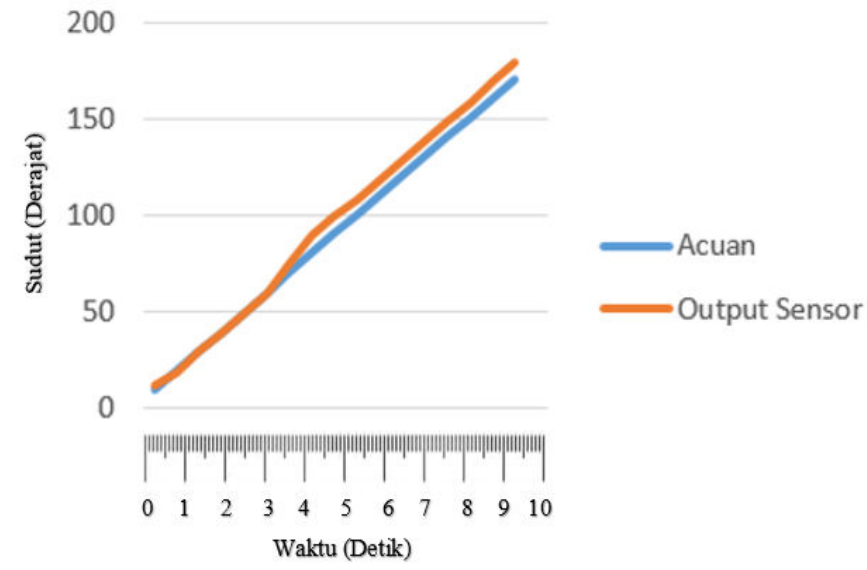

Gambar 13. Perbandingan keluaran sensor Yaw terhadap acuan.

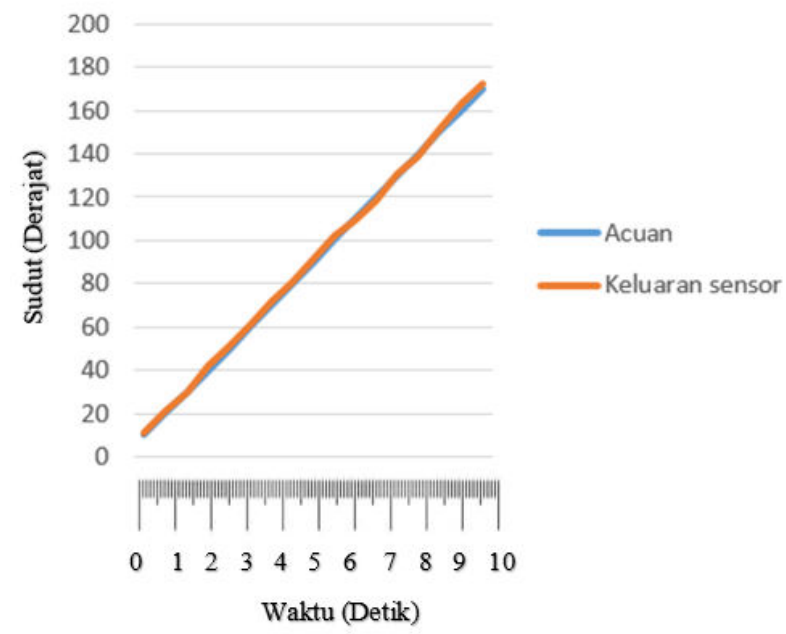

Gambar 14. Perbandingan keluaran sensor Roll terhadap acuan..

Pada gambar diatas menunjukkan bahwa keluaran dari sensor dan busur acuan memiliki linearitas yang cukup tinggi. Nilai galat yang diperoleh relative kecil, hal ini dapat kita lihat pada persamaan garis dibawah ini :

Persamaan garis untuk gambar IV.3:

$$
\mathrm{y}=1.0718 \mathrm{x}-1.4044
$$

Persamaan garis untuk gambar IV.4 :

$$
\mathrm{y}=0.9998 \mathrm{x}+0.9044
$$

\section{Pengujian Sistem keseluruhan}

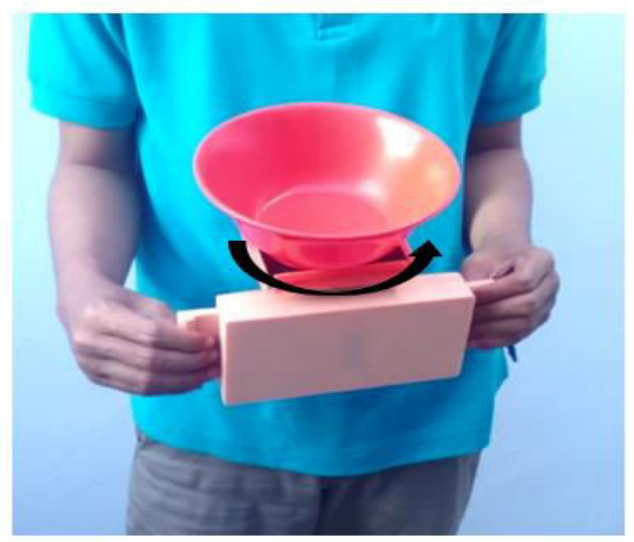

Gambar 15. Pengujian tanpa beban .

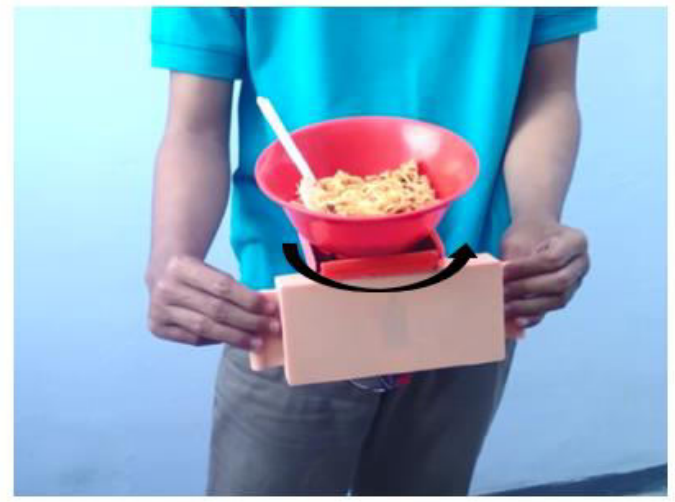

Gambar 16. Pengujian dengan beban.

Pengujian sistem keseluruhan bertujuan untuk melihat respon sistem yang telah diberi kontroler PID dengan pembacaan perubahan sudut terhadap respon aktuator yang dibaca oleh MPU6050. Pengujian ini dilakukan untuk mengetahui tingkat keberhasilan stabilisator, pengujian dilakukan terhadap 10 subjek yang beerbeda dengan dua kondisi yakni dengan beban dan tanpa beban. Pengujian sistem tanpa beban dilakukan dengan menjalanakan stabilisator dan menempatkan sebuah mangkuk diatas nampan guna mengetahui kestabilan. Pengujian dilakukan dengan dua keadaan yakni diam dan berjalan, dan diputar terhadap sumbu yaw serta pitch. Hasil pengujian dapat dilihat pada tabel 3 . Pengujian sistem dengan beban dilakukan dengan menjalanakan stabilisator dan menempatkan sebuah mangkuk yang telah diberi mie instan diatas nampan guna mengetahui kestabilan. Berat beban yang berupa mie instan mempunyai berat sebesar 70 Gram.

Tabel 3

Hasil Pengujian Tanpa Beban

\begin{tabular}{cllll}
\hline \hline No & Keadaan diam & & Keadaan berjalan & \\
\hline 1 & Subjek 1 & Berhasil & Subjek 1 & Berhasil \\
2 & Subjek 2 & Berhasil & Subjek 2 & Gagal \\
3 & Subjek 3 & Berhasil & Subjek 3 & Berhasil \\
4 & Subjek 4 & Berhasil & Subjek 4 & Berhasil \\
5 & Subjek 5 & Berhasil & Subjek 5 & Berhasil \\
6 & Subjek 6 & Berhasil & Subjek 6 & Berhasil \\
7 & Subjek 7 & Berhasil & Subjek 7 & Berhasil \\
8 & Subjek 8 & Berhasil & Subjek 8 & Gagal \\
9 & Subjek 9 & Berhasil & Subjek 9 & Gagal \\
\hline \hline
\end{tabular}

Tabel 4.

Hasil Pengujian Tanpa Beban

\begin{tabular}{cllll}
\hline \hline No & Keadaan diam & & Keadaan berjalan & \\
\hline 1 & Subjek 1 & Berhasil & Subjek 1 & Berhasil \\
2 & Subjek 2 & Berhasil & Subjek 2 & Gagal \\
3 & Subjek 3 & Gagal & Subjek 3 & Berhasil \\
4 & Subjek 4 & Berhasil & Subjek 4 & Gagal \\
5 & Subjek 5 & Berhasil & Subjek 5 & Gagal \\
6 & Subjek 6 & Gagal & Subjek 6 & Berhasil \\
7 & Subjek 7 & Gagal & Subjek 7 & Berhasil \\
8 & Subjek 8 & Berhasil & Subjek 8 & Gagal \\
9 & Subjek 9 & Berhasil & Subjek 9 & Berhasil \\
10 & Subjek 10 & Berhasil & Subjek 10 & Berhasil \\
\hline \hline
\end{tabular}

Berdasarkan hasil uji tanpa beban pada tabel diatas didapatkan success rate untuk stabilisator ketika sistem tanpa beban adalah sebesar 100\% untuk keadaan diam dan $60 \%$ ketika keadaan berjalan. Sedangkan pada keadaan dengan 
beban didapatkan success rate sebesar $70 \%$ pada keadaan diam dan $60 \%$ saat keadaan berjalan.

\section{KESIMPULAN}

Berdasarkan data hasil uji implementasi alat stabilisator nampan ini didapatkan kesimpulan antara lain terdapat komponen yang penting dalam sistem ini yakni IMU Sensor dan Motor Servo sebagai actuator. Nilai pembacaan IMU sensor masih harus deprogram lebih lanjut karena nilainya terus naik sedikit sehingga mempengaruhi dalam pembacaan. Besarnya nilai konstanta proporsional untuk sistem ini yakni 10, karena apabila nilai tersebut ditambah maka akan terjadi osilasi pada sistem dan sulit dalam mencapai kestabilan. MPU6050 mampu mendeteksi perubahan sudut dengan error rata-rata sebesar 3,17\% untuk sumbu pitch sedangkan error rata-rata untuk sumbu yaw sebesar $0,2 \%$. Hasil pengujian sistem success rate stabilisator ketika sistem tanpa beban adalah sebesar $100 \%$ untuk keadaan diam dan $60 \%$ ketika keadaan berjalan. Sedangkan pada keadaan dengan beban didapatkan success rate sebesar $70 \%$ pada keadaan diam dan $60 \%$ saat keadaan berjalan.

\section{DAFTAR PUSTAKA}

[1] G. David and A. Cathi, Parkinson's Disease Handbook. New York: Medtronic.

[2] J. G. Nutt and G. F. Wooten, "Diagnosis and Initial Management of Parkinson's Disease," N. Engl. J. Med., vol. 353, no. 10, 2005.

[3] J. Qiao and Z. Liu, "Gain Scheduling PID Control Of The QuadRotor Helicopter," IEEExplore, 2017.

[4] A. Sahib, S. R. A. Monaf, A. M. Din, and J. Tafila., "Rotor Position Detection And Control For Spindle Brushless Dc Motors Using Dummy Windings," IEEEXplore, 2013.

[5] Bhilai and SSTC, "Comparative Study of P, PI and PID Controller
forSpeed Control of VSI-Fed Induction Motor," IEEExplore, 2014.

[6] H. Bolandi, M. Rezaei, R. Mohsenipour, H. Nemati, and M. Smailzadeh, "Attitude Control of a Quadrotor with Optimized PID Controller," Intell. Control Autom., vol. 4, no. 3, 2013.

[7] K. Bansal and L. Dewan, "Stabilization Of A Gimbal Sistem Using Pid Control And Compensator-A Comparison," Int. J. Electr. IEEExplore, 2015.

[8] D. Ibrahim, Microcontroller-Based Temperature Monitoring and Control. Oxford: Newnes, 2002.

[9] H. N. Budi, B. S. Kemalasari, and A. Wijayanto, "Pengaturan Posisi Motor Servo DC Dengan Metode P, Pi, Dan Pid," POMITS, vol. 1, pp. 1-9, 2008.

[10] Datasheet MPU-6050, "MPU-6000 and MPU-6050 product specification," 2018.

[11] M. F. Alwi, M. Rivai, and Suwito., "Perancangan Sistem Stabilisasi Kamera Tiga Sumbu Dengan Metode Kontrol Fuzzy Untuk Mobile Surveillance Robot," J. Tek. ITS.

[12] D. Rodríguez-Martín, A. Carlos Pérez-López, J. C. Samà, and A. Català, "A Wearable Inertial Measurement Unit for Long-Term Monitoring in the Dependency Care Area," Sensors, vol. 13, no. 12, 2013.

[13] M. H. Daware and A. S. Patil, "Implementation of I2C Bus Protocol on FPGA," Int. J. Curr. Eng. Sci. Res., vol. 2015, 2015.

[14] H. Ardiansyah, M. Rivai, and L. Prihadi Eka Nurabdi, "Train arrival warning system at railroad crossing using accelerometer sensor and neural network," in AIP Conference Proceedings, 2018.

[15] A. A. Kurniawan, M. Rivai, and F. Budiman, "Sistem Pemandu Pendaratan Pada Balon Udara Berbasis Pengolahan Citra Dan Kendali PID," J. Tek. ITS, vol. 5, no. 2, pp. A179-A184, 2016.

[16] Datasheet Motor Servo, "Motor Servo sg90 datasheet."

[17] M. Asfari, M. Rivai, and Tasripan, "Penentuan Arah Sumber Suara dengan Metode Interaural Time Difference menggunakan Mikrokontoler STM32F4," J. Tek. ITS, 2017.

[18] M. Rivai, M. Suwito, P. Chondro, and S.-J. Ruan., "Design and Implementation of a Submerged Capacitive Sensor in PID Controller to Regulate the Concentration of Non-Denatured Ethyl Alcohol," IEEE, pp. 45-50, 2015.

[19] R. Setiawan, M. Rivai, and Suwito, "Implementasi Analog Front End Pada Sensor Kapasitif Untuk Pengaturan Kelembaban Menggunakan Mikrokontroller STM32," J. Tek. I, 2017. 